\title{
Analysis of a Recent Biofilter Model for Toluene Biodegradation
}

\author{
Muhammad Qasim, Zarook Shareefdeen* \\ Department of Chemical Engineering, American University of Sharjah, Sharjah, UAE \\ Email: "zshareefdeen@aus.edu
}

Received September 29, 2012; revised October 30, 2012; accepted November 9, 2012

\begin{abstract}
This paper investigates and provides a critical analysis of the toluene biofilter model developed by Li and De Visscher. The model simulation results have been reproduced and compared with several sets of experimental data from literature. Three different model variations are considered: model with no substrate inhibition, with substrate inhibition, and with air flow rate modification. A sensitivity analysis has been performed on model to study the effect of important parameters on the removal efficiency. Model limitations and improvements have been highlighted.
\end{abstract}

Keywords: Air Pollution; Biofilter; Modeling; Toluene; Volatile Organic Compound

\section{Introduction}

The upsurge of strict environmental regulations to maintain good air, soil and water quality requires the use of proper pollution control and pollution prevention equipment. Traditional pollution control technologies such as incineration, carbon adsorption and wet-scrubbing may be used to control pollution. However, these conventional techniques are becoming more expensive due to more stringent environmental regulations [1]. In the field of pollution control, biological treatment such as biofiltration is continuing to gain attention as an alternative to the conventional techniques.

Biofiltration is a pollution control technique that uses living microorganisms to capture and degrade pollutants from air. It is a process that combines basic mechanisms of adsorption, biodegradation and desorption of gas phase pollutants [2]. A biofilter is simply a packed bed that utilizes a packing material with microorganisms such as bacteria immobilized as biofilm on the surface and the pore structures of the packing material. The packing material may be particles such as peat, compost, peat/perlite mixture or organic or inorganic commercial media materials. The flow of contaminated air through the biofilter results in the degradation of the pollutants by the immobilized microorganisms. Biofilter performance is affected by a number of factors such as the composition and relative humidity of the waste stream, airflow velocity, temperature and $\mathrm{pH}$ of the biofilter bed, the pore size distribution, and other structural characteristics [1]. The surface of the porous material in the biofilter is covered with

${ }^{*}$ Corresponding author. biofilms which are made of microorganisms. Treatment begins with the transfer of the contaminants from the air stream to the biofilm phase. Then, the dissolved contaminant is moved by diffusion and by advection in the air. Biotransformation finally converts the contaminant to biomass, metabolic by-products, carbon dioxide and water.

Several types of biofilters have been developed, the most typical of which include bioscrubbers, trickling bed biofilter and packed bed biofilter [3]. In all these technologies, pollutants in the gas stream are transferred to the biofilm and are degraded by the microorganisms. The bioscubber consists of a scrubber and a bioreactor. In the scrubber, water is sprayed counter-current to the polluted gas flow resulting in absorption of the pollutant into the water. This water is then directed to a bioreactor containing activated sludge where microorganisms degrade the pollutants. The trickling bed biofilter, on the other hand, relies on the inert packing media to support bacterial growth. The packed bed biofilter does not use a large continuous flow of water. The media used in the packed bed biofilter acts as a water reservoir as well as a support structure for the bacteria.

Figure 1 shows a simplified schematic of a biofilter [3].

\section{Review on Biofilter Models}

The design and scale-up of biofilters requires development of realistic mathematical models [4]. Many mathematical biofilter models have been developed in an effort to improve our understanding of biofilters, to guide ex- 


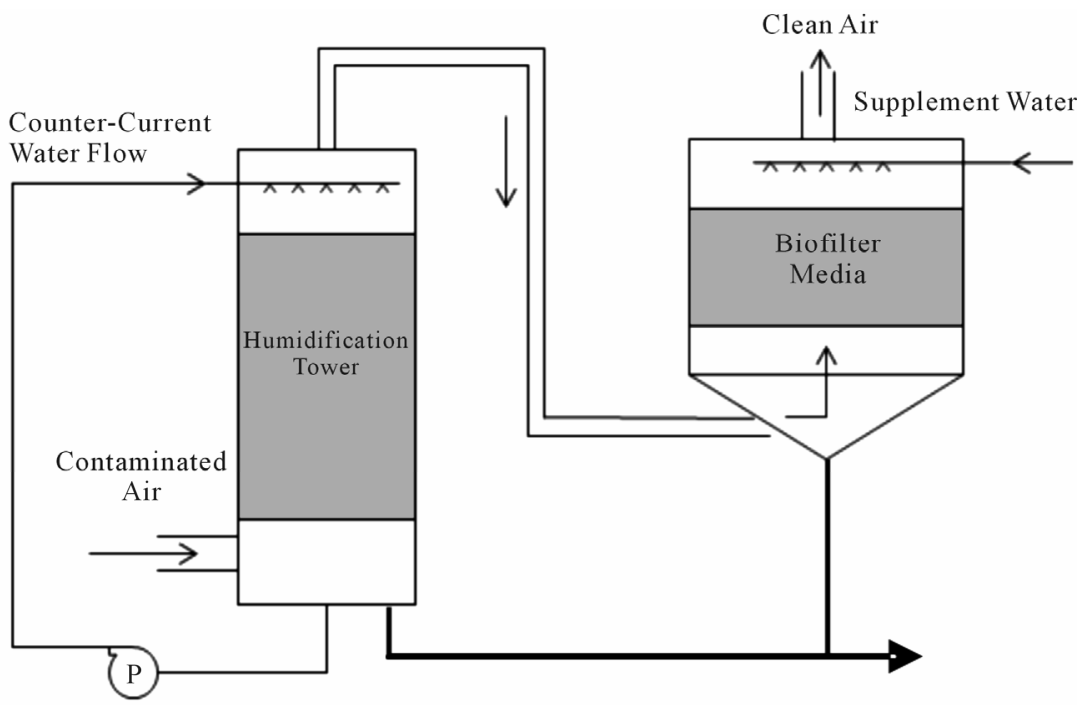

Figure 1. Simplified biofilter schematic.

perimentation, and to improve the biofilter design, performance and scale-up [5]. Most of these models are based on several assumptions and may be simple or complex models. Over the years, researchers have developed more and more complex biofilter models that accurately describe the biofilter performance and provide a more rational approach to biofilter design. While there has been significant success among investigators in describing and understanding laboratory results of biofilters, no single model has become of a standard that is generally accepted [5]. Different models have been developed that use different approaches to describe the pollutant degradation, biofilm growth and biofilter performance. Some of the biofilter models are very simple and consider no growth or mass-transfer limitations [6].

Ottengraf and van der Oever [7] developed the first steady-state biofilter model for the biofiltration of single volatile organic compounds (VOC) in 1980s. In this early model, both diffusion and biodegradation of pollutants in the biofilm were considered. In particular, Ottengraf and van der Oever considered three cases in their model: first-order kinetics, zero-order kinetics with reaction rate limiting, and zero-order kinetics with diffusion rate limiting. The basic assumptions in the model included smaller biofilm thickness compared to the diameter of support particles and that the gas phase is in plug flow. Ottengraf and van der Oever model is the most widely used biofilter model since it is easy to implement.

Later Shareefdeen et al. [8] extended the work of Ottengraf and proposed a biofilter model to describe the steady-state performance of biofilters. This model includes both oxygen and substrate inhibition effects and oxygen is not assumed to be limiting as in the case of the model by Ottengraf and van der Oever [7]. Later, Shareefdeen and Baltzis [9] modified the model by Shareef- deen et al. [8] and proposed the partial coverage of the support particles by biofilms, leaving the bare surfaces of the particles in direct contact with the airstream. Furthermore, Shareefdeen and Baltzis proposed that the uncovered surfaces can adsorb the substrate, and that the adsorption follows the Freundlich isotherm. These two models have a wide range of applicability but require input data that are not easily available.

Similar to the model of Shareefdeen et al. [8], Deshusses et al. [10,11] developed a dynamic diffusionreaction model to describe the steady-state as well as transient behavior of biofilters. This model considers a first order exchange rate between biomass layers and also includes the substrate inhibition effects.

Several biofilter models have been developed in recent years. Almost all of these models have been developed based on these earlier biofilter models. The biofilter model by Deshusses et al. was modified in 2006 by Park and Jung [12] by using Luong kinetics for substrate inhibition instead of Michaelis-Menten kinetics. This model is used to study biofiltration of toluene under high load conditions.

Yang et al. [13] developed a new biofilter model for the biofiltration of toluene in a rotating drum biofilter. This model takes into account a variable biofilm thickness. According to this model, the biofilm thickness increases by microbial growth. As a result, this model becomes rather complicated.

Babu and Raghuvanshi [2] proposed a transient mathematical model for biofilter operation and biofiltartion of VOCs in periodic mode. Under transient conditions, the uncovered surface of the solid support in the biofilter can adsorb the pollutants. Therefore, in this model, adsorption process is accounted explicitly. The model assumes axial dispersion flow for the gas and a linear driving 
force to approximate the pollutant or contaminant interphase transport. It also assumes pollutant adsorption and biodegradation in the solid support using first order kinetics with no oxygen limitation.

Liao et al. [14] developed a mathematical model for gas-liquid two phase flow and biodegradation in a trickling biofilter subjected to low concentration of VOC. The model simplifies the packed biofilter as a series of capillary tubes covered by the biofilm. The model assumes that the biofilm is formed on the exterior surface of the packed material and thus no reaction occurs in the pores of the packed material. The absorption of the VOC pollutant at the gas-liquid interface is evaluated using Henry's law. In short, the model incorporates the effect of pollutant adsorption at gas-liquid interface, the mass transfer resistance in the liquid zone and the biofilm zone, the biochemical reaction in the biofilm, and the limitation of oxygen for the microbial growth.

Chen et al. [15] described a model for removal of nitric oxide in a rotating drum biofilter. The model is based on mass balance of the pollutant in the gas, liquid, and biofilm phases. Based on the mass component profile of $\mathrm{NO}$ at the gas-liquid interface combined with Monod kinetic equation, the model predicts the mass transfer-reaction process of NO in the rotating bed biofilter.

The mathematical model developed by Spigno et al. [16] for phenol degradation in biofilters assumes no oxygen limitation, no reaction inside the pores of the solid material, fast gas-solid transfer compared to diffusion and reaction in the biofilm, uniform biofilm properties, and Monod kinetics to describe the biofilm growth.

Biofiltration of ammonia has been recently studied by Baquerizo et al. [17]. The mathematical model is based on discretized mass balances and nitrification kinetics that include inhibitory effects caused by free nitrous acid and free ammonia in the biofilter. The model includes most of the known biofiltration phenomenon and accounts for advection, absorption, adsorption, diffusion and biodegradation. In addition, all biological inhibitions occurring in the nitrification process and oxygen limitation in the kinetic model have been considered. In general, the model is able to predict ammonia shock-loadings and the biofilter behavior under inhibitory conditions.

Lu et al. [18] described the biofiltration of isopropyl alcohol and acetone mixtures assuming pseudo-steadystate operating conditions. The model neglects the convective transport within the biofilm. Chimel et al. [19] developed a concise model for VOC removal in periodic operation of biofilters. Under periodic operation, the biofilm is assumed to be less developed than under continuous regime, due to temporal nutrient shortages. A linear driving force is used to approximate the pollutant interphase transport. The model also allows for the pol- lutant adsorption and biodegradation in the support phase using the first-order kinetics with no oxygen limitation.

Toluene is one of the most widely released air pollutants. It is used extensively in fuels, solvents and as raw material for production of other chemicals [20]. Studies in humans and animals have demonstrated that toluene is readily absorbed via the lungs and the gastrointestinal tract. In humans, exposure to toluene causes central nervous system depression and may also act as a narcotic in case of large dosage. Chronic occupational exposure and incidences of toluene abuse have resulted in heaptomegaly and liver function changes [21]. Thus, effective removal of toluene from contaminated gas and liquid streams becomes important.

The objective of this paper is to analyze and investigate the validity of the model of Li and De Visscher [22] for biofiltration of toluene contaminated air. This model is based on the model by De Visscher and Van Cleemput [23] for methane biodegradation in landfill cover soils. Li and De Visscher [22] used the model by De Visccher and Van Cleepmput [23] to study toluene biofiltration, and modified the model equation to include substrate inhibittion using Haldane kinetics and influence of gas flow rate on toluene degrading activity.

\section{Toluene Biofilter Model of Li and De Visscher [22]}

In this section the biofilter model of Li and De Visscher [22] is presented so that the readers can follow the analysis and discussion presented in the subsequent sections.

In the toluene biofilter model by $\mathrm{Li}$ and De Visscher, the biofilter is considered as a plug flow reactor. The height of the biofilter is divided into a number of subsections and the mass balance in each of these subsections is given as follows:

$$
Q \cdot C_{j}=Q \cdot C_{j+1}+r_{j} A \Delta z
$$

where $Q$ is the air flow rate $\left(\mathrm{m}^{3} / \mathrm{h}\right)$, A is cross-sectional area of the biofilter $\left(\mathrm{m}^{2}\right), C_{j}$ and $C_{j+1}$ are concentrations $\left(\mathrm{g} / \mathrm{m}^{3}\right)$ of the gas-phase pollutant (toluene) in the subsections $j$ and $j+1$ respectively, $\Delta z$ is the subsection height $(\mathrm{m})$, and $r_{j}$ is the volumetric biodegradation rate $\left(\mathrm{g} / \mathrm{m}^{3}\right.$ biofilter/h) in the subsection $\mathrm{j}$ of the biofilter.

Equation (1) can be written in the following differential form with the biofilter height $z$ as the independent variable:

$$
\frac{\mathrm{d} C}{\mathrm{~d} z}=-\frac{A}{Q} r
$$

The expression for the volumetric biodegradation rate $r$ depends on whether substrate inhibition is considered or not. On the basis of Pirt kinetics [24] and logistic growth rate expression, De Visscher and Van Cleemput 
[23] developed the following expression for microbial growth for methane biofiltration:

$$
\mu=\mu_{\max }^{\prime} \frac{\left[1-\frac{V_{\text {max }}}{V_{\text {max } \max }}\right] S}{K_{m}+S}-a
$$

where $V_{\max }$ is the maximum degradation rate (g pollutant $/ \mathrm{m}^{3}$ biofilter $\left./ \mathrm{h}\right), V_{\max , \max }$ is the maximum attainable value of $V_{\max }$ (g pollutant $/ \mathrm{m}^{3}$ biofilter $\left./ \mathrm{h}\right), S$ is the substrate concentration in the liquid phase $\left(\mathrm{g} / \mathrm{m}^{3}\right), K_{m}$ is the Michaelis-Menten constant $\left(\mathrm{g} / \mathrm{m}^{3}\right)$, a is the decay rate of the microbes $\left(\mathrm{h}^{-1}\right), \mu$ is the specific growth rate $\left(\mathrm{h}^{-1}\right)$, and $\mu_{\max }$ is the actual maximum specific growth rate $\left(\mathrm{h}^{-1}\right)$. The change of $V_{\max }$ with time is given by the following equation:

$$
\frac{\mathrm{d} V_{\max }}{\mathrm{d} t}=\mu V_{\max }
$$

De Visscher and Van Cleemput [23] proposed that $V_{\max }$ attains a maximum value $V_{\max , \max }$ during the course of biofiltration. Most biofilter models assume a uniform biofilm structure and a constant $V_{\max }$ throughout the biofiltration process. However, in reality, the thickness of bio-layer changes with substrate concentration and thus changes with the position in the biofilter [25]. The biofilm is expected to grow the thickest where the substrate concentration is the highest. Therefore, $V_{\max }$ is not constant along the biofilter height.

\subsection{Biofilter Model 1 (without Substrate Inhibition)}

If substrate inhibition is not considered, the volumetric biodegradation rate $r_{j}$ is given by Michaelis-Menten kinetics:

$$
r_{j}=V_{\max , j} \frac{S_{j}}{K_{m}+S_{j}}
$$

where $S_{j}$ is the liquid-phase concentration $\left(\mathrm{g} / \mathrm{m}^{3}\right)$ of the pollutant and is related to $C_{j}$ by Henry's law as follows:

$$
S_{j}=\frac{C_{j}}{H_{c c}}
$$

where $H_{c c}$ is the dimensionless Henry's constant for the pollutant. In each subsection, the microbial growth rate is given by De Visscher and Van Cleemput [23] model:

$$
\mu_{j}=\mu_{\max }^{\prime} \frac{\left[1-\frac{V_{\max , j}}{V_{\max , \max }}\right] S_{j}}{K_{m}+S_{j}}-a
$$

At steady state, there is no net microbial activity $\left(\mu_{j}=\right.$ 0 ) and Equation (7) can be written as follows:

$$
V_{\max , j}=\left[1-\frac{a}{\mu_{\max }^{\prime}}\left(1+\frac{K_{m}}{C_{j} / H_{c c}}\right)\right] V_{\max , \max }
$$

Equation (8) indicates that the $V_{\max }$ is not constant but changes with the pollutant concentration at different biofilter height positions. Equation (2) combined with Equation (5) and Equation (8) can be solved numerically to study the pollutant concentration along the biofilter height.

\subsection{Biofilter Model 2 (with Substrate Inhibition)}

In case of substrate inhibition, Haldane kinetics [26] gives the following expression for the microbial growth rate:

$$
\mu_{j}=\mu_{\max }^{\prime} \frac{\left[1-\frac{V_{\max , j}}{V_{\max , \max }}\right] S_{j}}{K_{m}+S_{j}+\frac{S_{j}^{2}}{K_{I}}}-a
$$

where $K_{I}$ is the inhibition constant $\left(\mathrm{g} / \mathrm{m}^{3}\right)$. Similarly, the volumetric biodegradation rate assumes the following form:

$$
r_{j}=V_{\max , j} \frac{S_{j}}{K_{m}+S_{j}+\frac{S_{j}^{2}}{K_{I}}}
$$

Again, under steady-state, $\mu_{j}$ becomes equal to zero and Equation (9) becomes as follows:

$$
V_{\max , j}=\left[1-\frac{a}{\mu_{\max }^{\prime}}\left(1+\frac{K_{m}}{\frac{C_{j}}{H_{c c}}}+\frac{C_{j}}{H_{c c} K_{I}}\right)\right] V_{\text {max }, \text { max }}
$$

In case of substrate inhibition, Equation (2) combined with Equations (10) and (11) can be solved numerically to study the pollutant concentration along the biofilter height.

\subsection{Biofilter Model 3 (with Flow Rate Modification)}

The performance of a biofilter is significantly affected by the flow rate of air. At high air flow rates, the biofilm layer becomes thinner and more uniform [27], and mass transfer and biodegradation are favored [22]. For biofilters operating under varying air flow rates with substrate inhibition (model 2), an empirical equation is used to describe the effect of air flow rate $Q$ on the value of $V_{\text {max,max }}[22]$ :

$$
V_{\text {max, } \max }^{\prime}=V_{\text {max,max }} Q^{p}
$$


where $V_{\max , \max }^{\prime}$ is the flow-rate-modified maximum value of $V_{\max , \max }$. The value of $p$ is between 0 and 1 [22]. To include the effect of varying air flow rate, Equation (12) replaces $V_{\max \text { max }}$ in Equation (11) of model 2. The equations can then be solved to study the concentration of pollutant along the biofilter height.

\section{Results and Discussion}

\subsection{Biofilter Model 1 (without Substrate Inhibition)}

The non-linear coupled differential equations made up of Equations (2), (5) and (8), are solved using the ODE command in MATLAB to describe the variation of gasphase toluene concentration along the biofilter height for the case where substrate inhibition is neglected. [28]

Model 1. Verification Using the Data of Zamir et al.

Li and De Visscher [22] validated their model with the experimental results of Aizpuru et al. [29]. These results are also reproduced and are in good agreement as reported by Li and De Visscher [22]. The model of Li and De Visscher [22] was also solved and verified using the data of Zamir et al. [28]. Fungi were used as the toluenedegrading microorganisms. The biofilter had an inner diameter of $9.9 \mathrm{~cm}$, a total height of $75 \mathrm{~cm}$ and an effecttive volume of $4 \mathrm{~L}$ (empty basis) and consisted of three stages. A mixture of powdered compost supplied acted as packing material. The parameters required for model 1 solution are summarized in Table 1.

Since fungi were used for biodegradation, substrate inhibition can be neglected and model 1 can be used to predict the gas-phase toluene concentration along the biofilter height. Figure 2 shows a good agreement between the model simulation results and the experimental

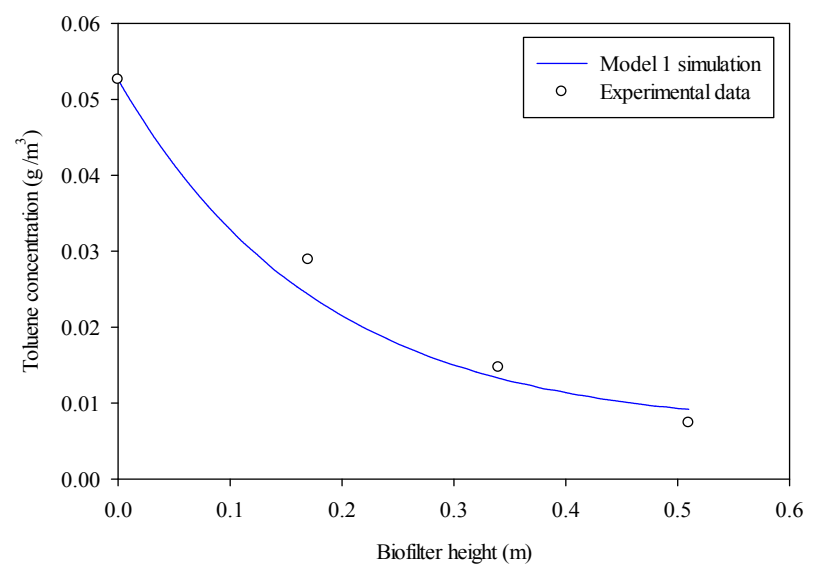

Figure 2. Model 1 (no substrate inhibition) prediction of toluene gas-phase concentrations along the biofilter height. Toluene-contaminated air flow rate is $0.06 \mathrm{~m}^{3} / \mathrm{h}$, inlet toluene gas-phase concentration is $0.0526 \mathrm{~g} / \mathrm{m}^{3}$, experimental data adopted from Zamir et al. [28].
Table 1. Model 1 parameters (no substrate inhibition) [28].

\begin{tabular}{cccc}
\hline Parameter & Value & Unit & Source \\
\hline$\mu_{\max }^{\prime}$ & 0.28 & $\mathrm{~h}^{-1}$ & {$[30,31]$} \\
$K_{m}$ & 3.495 & $\mathrm{~g} / \mathrm{m}^{3}$ & {$[22]$} \\
$a$ & 0.0017 & $\mathrm{~h}^{-1}$ & {$[32]$} \\
$V_{\max , \max }$ & 50 & $\mathrm{~g}$ pollutant $/ \mathrm{m}^{3}$ biofilter $/ \mathrm{h}$ & {$[32]$} \\
$H_{c c}$ & 0.313 & - & {$[33]$} \\
\hline
\end{tabular}

results adopted from Zamir et al. [28].

Therefore, in cases where substrate inhibition can be neglected, such as use of fungi for biodegradation or low toluene loading, model 1 developed by Li and De Visscher [22] showed excellent agreement with the two sets different experimental data as described by Li and De Visscher [22] and also Figure 2.

\subsection{Biofilter Model 2 (with Substrate Inhibition)}

When the substrate loading is very high or the microorganisms used for biodegradation are not fungi, substrate inhibition needs to be taken into account. This corresponds to model 2 developed earlier. In this case, the Equation (2) combined with Equations (10) and (11) can be solved to study the variation of gas-phase toluene concentration along the biofilter height.

Model 2. Verification using the Data of Park and Jung [12]

The model 2 is solved, reproduced and compared with experimental results of Park and Jung [12]. Table 2 shows the parameters which were used to solve the biofilter model as per Park and Jung [12].

The experiments conducted by Park and Jung [12] for toluene biofiltration were carried out in three biofilters in series, each packed with spherical ceramic packing. The total packing height was $0.54 \mathrm{~m}$. Pseudomonas pudita $\mathrm{F} 1$ stains were used as toluene-degrading microorganisms. A volumetric loading rate of $35.6 \mathrm{~m}^{3} \mathrm{air} / \mathrm{m}^{3}$ biofilter $/ \mathrm{h}$ was used. Figure 3 shows the solution of model 2 with substrate inhibition and comparison with the experimental results. Reproduced model solutions and experimental data are in good agreement.

To verify the importance of inhibition effects, the model 1 (substrate with no inhibition model) is solved and compared with the same set of experimental data of Park and Jung [12]. Figure 4 shows the simulation results using model 1 and parameters in Table 2 in case if the substrate inhibition were neglected. Figure 4 clearly indicates that neglecting the substrate inhibition gives poor agreement.

In the case of Park and Jung [12], Pseudomonas pudita F1 stains were used as toluene-degrading microor- 
Table 2. Model 2 parameters (including substrate inhibition) [12].

\begin{tabular}{cccc}
\hline Parameter & Value & Unit & Source \\
\hline$\mu_{\max }^{\prime}$ & 0.58 & $\mathrm{~h}^{-1}$ & {$[34-38]$} \\
$K_{m}$ & 5.34 & $\mathrm{~g} / \mathrm{m}^{3}$ & {$[22]$} \\
$a$ & 0.0017 & $\mathrm{~h}^{-1}$ & {$[32]$} \\
$V_{\max , \max }$ & 123.1 & $\mathrm{~g}$ pollutant $/ \mathrm{m}^{3}$ biofilter $/ \mathrm{h}$ & {$[22]$} \\
$K_{I}$ & 2.66 & $\mathrm{~g} / \mathrm{m}^{3}$ & {$[22]$} \\
$H_{c c}$ & 0.276 & - & {$[33]$} \\
\hline
\end{tabular}

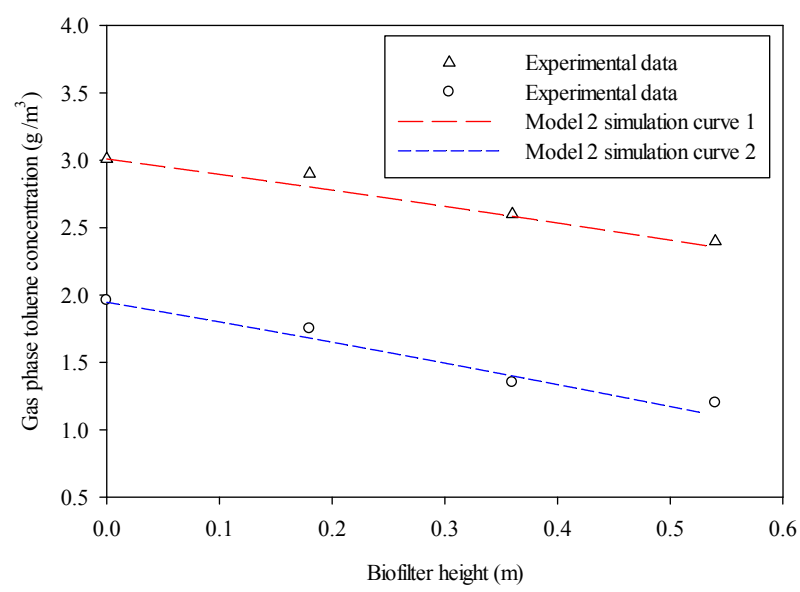

Figure 3. Model 2 (with substrate inhibition) prediction of toluene gas-phase concentrations along the biofilter height. Toluene-contaminated air volumetric loading is $35.6 \mathrm{~m}^{3} / \mathrm{m}^{3}$ biofilter/h, curve 1: Inlet toluene gas-phase concentration is $3.01 \mathrm{~g} / \mathrm{m}^{3}$, curve 2 : Inlet toluene gas-phase concentration is $1.96 \mathrm{~g} / \mathrm{m}^{3}$, experimental data adopted from Park and Jung [12].

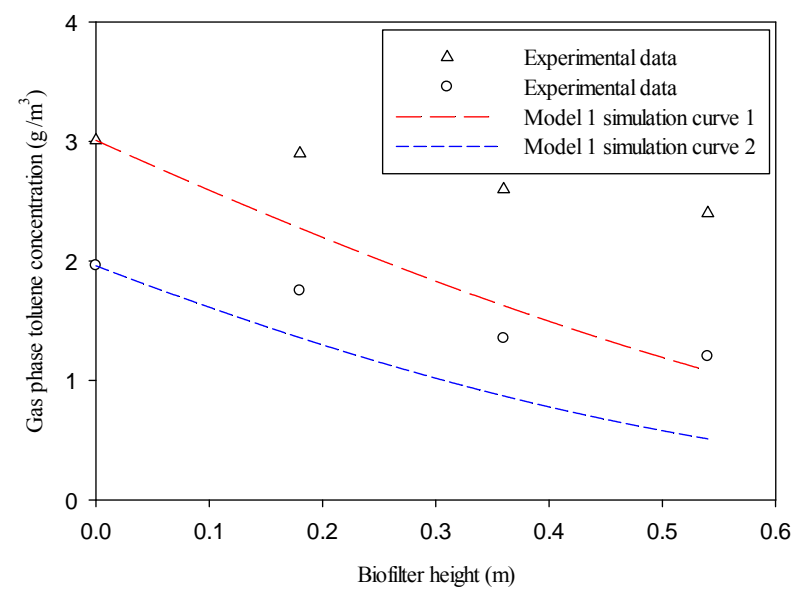

Figure 4. Model 1 (no substrate inhibition) prediction of toluene gas-phase concentrations along the biofilter height. Toluene-contaminated air volumetric loading is $35.6 \mathrm{~m}^{3} / \mathrm{m}^{3}$ biofilter/h, curve 1: Inlet toluene gas-phase concentration is $3.01 \mathrm{~g} / \mathrm{m}^{3}$, curve 2 : Inlet toluene gas-phase concentration is $1.96 \mathrm{~g} / \mathrm{m}^{3}$, experimental data adopted from Park and Jung [12]. ganisms and substrate inhibition becomes important. On the other hand, the experiments by Aizpuru et al. [29] used fungi as the toluene-biodegrading microorganisms for which substrate inhibition was negligible [22]. These analyses demonstrate careful selection of the model and the kinetics of biodegradation.

\subsection{Biofilter Model 3 (with Flow Rate Modification)}

Model 3 developed by Li and De Visscher [22] accounts for the effect of varying air flow rate. In this case, Equation (2) combined with Equations (10)-(12) must be solved simultaneously.

The model solutions are reproduced and were compared with experimental results of Vergara-Fernándaz et al. [38]. The parameters used to solve model 3 are summarized in Table 3.

Their experiments were carried out at $32^{\circ} \mathrm{C}-37^{\circ} \mathrm{C}$ in a toluene-degrading biofilter subjected to varying air flow rates. Compost and seashells were used as a packing material with microbial flora present in the compost. The height and diameter of the biofilter were $0.75 \mathrm{~m}$ and $0.145 \mathrm{~m}$, respectively. Inhibition is considered in this case [39]. The solution to model 3 using the parameters in Table 3 are obtained for four different flow rates 0.12 , $0.18,0.24$ and $0.73 \mathrm{~m}^{3} / \mathrm{h}$. Figure 5 shows the simulation results with the experimental data from VergaraFernándaz et al. [38] for the flow rate of $0.12 \mathrm{~m}^{3} / \mathrm{h}$. On the same graph, experimental results were also compared with model 2 which neglect the effect of air flow rate variation. Model 2 shows wider variation with the experimental data than the simulation results presented by $\mathrm{Li}$ and De Visscher [22]. This indeed confirms that flow rate modification is an important factor which should not be ignored.

\subsection{Sensitivity Analysis}

\subsubsection{Effect of Actual Maximum Growth Rate $\left(\mu_{\max }^{\prime}\right)$}

A sensitivity analysis of model $1-3$ is performed to study the effect of the actual maximum specific growth rate $\left(\mu_{\max }^{\prime}\right)$ on the removal efficiency of toluene. The effect of changing $\mu_{\max }^{\prime}$, with all other parameters fixed as in Table 1 is shown in Figure 6. An increase in $\mu_{\max }^{\prime}$ leads to an increase in the removal efficiency of toluene in case of model 1. However, percent removal efficiency (\%RE) asymptotically reaches a maximum value at $\mu_{\max }^{\prime}$ of $0.70 \mathrm{~h}^{-1}$. In case of model 2 (with substrate inhibition), the effect of changing $\mu_{\max }^{\prime}$, while keeping other parameters in Table 2 constant, is shown in Figure 7. Again, an increase in the maximum specific growth rate increases the removal efficiency up to a certain limit, after which the change is negligible. Since model 3 is 
Table 3. Model 3 parameters (with flow rate modification) [38].

\begin{tabular}{cccc}
\hline Parameter & Value & Unit & Source \\
\hline$\mu_{\max }^{\prime}$ & 0.12 & $\mathrm{~h}^{-1}$ & {$[39]$} \\
$K_{m}$ & 11.1 & $\mathrm{~g} / \mathrm{m}^{3}$ & {$[22]$} \\
$a$ & 0.0017 & $\mathrm{~h}^{-1}$ & {$[32]$} \\
$K_{I}$ & 95.5 & $\mathrm{~g} / \mathrm{m}^{3}$ & {$[22]$} \\
$V_{\max , \max }$ & 869.3 & $\mathrm{~g}$ pollutant $/ \mathrm{m}^{3}$ biofilter $/ \mathrm{h}$ & {$[22]$} \\
$p$ & 0.6325 & - & {$[22]$} \\
$H_{c c}$ & 0.422 & - & {$[33]$} \\
\hline
\end{tabular}

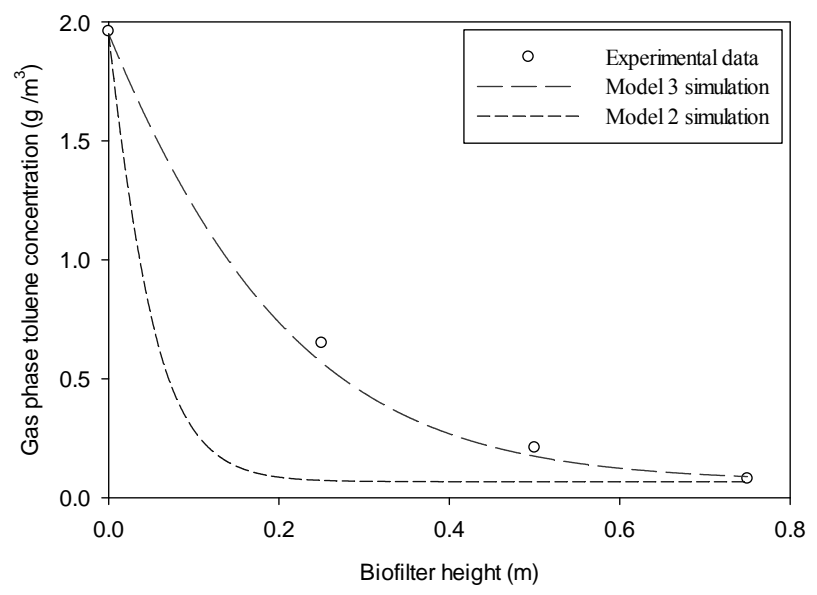

Figure 5. Model 3 (with flow rate modification) prediction of toluene gas-phase concentrations along the biofilter height. Toluene-contaminated air volumetric flow rate is $0.12 \mathrm{~m}^{3} / \mathrm{h}$, inlet toluene gas-phase concentration is $1.95 \mathrm{~g} / \mathrm{m}^{3}$, experimental data adopted from Vergara-Fernándaz et al. [38].

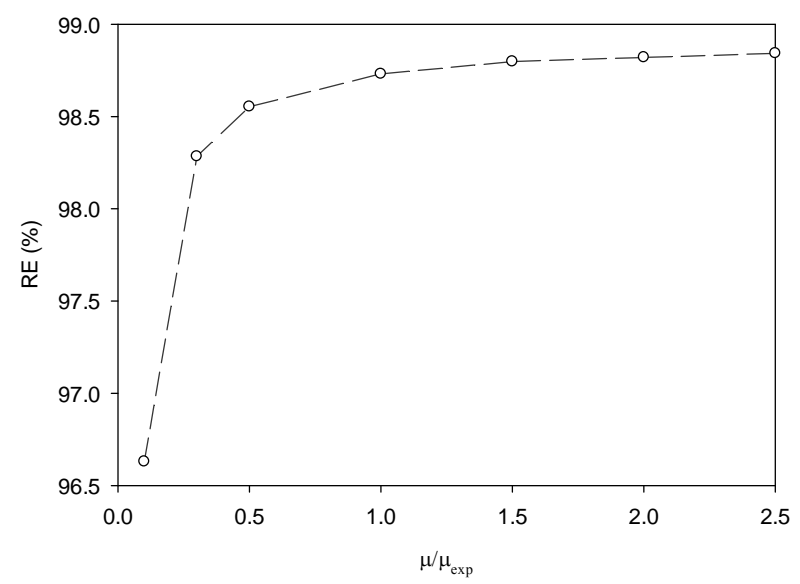

Figure 6. Effect of changing $\mu_{\max }^{\prime}$ in model 1 (no substrate inhibition) on removal efficiency (RE). Toluene-contaminated air volumetric loading is $77.6 \mathrm{~m}^{3} / \mathrm{m}^{3}$ biofilter/h, inlet toluene gas-phase concentration is $4.6 \mathrm{~g} / \mathrm{m}^{3}, \quad \mu_{\text {max,experimental }}^{\prime}$ is $0.28 \mathrm{~h}^{-1}$. very similar to model 2 , the effect of changing the actual maximum specific growth rate will be the same as in case of model 2.

\subsubsection{Effect of Michaelis-Menten Constant $\left(K_{m}\right)$}

The effect of changing the Michaelis-Menten constant $\left(K_{m}\right)$ on the removal efficiency was studied. In case of model 1, all parameters in Table 1 were fixed and the Michaelis-Menten constant was changed. The experimental $K_{m}$ value was $1.24 \mathrm{~g} / \mathrm{m}^{3}$. The effect of changing $K_{m}$ on removal efficiency in model 1 is depicted in Figure 8. For mode1 1 that neglects substrate inhibition, an increase in the value of the Michaelis-Menten constant $\left(K_{m}\right)$ results in a decrease in removal efficiency. The

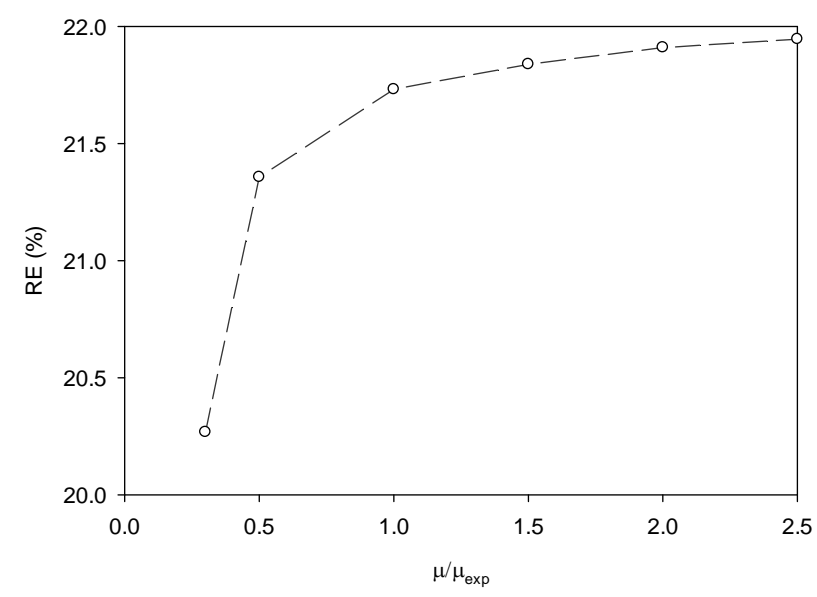

Figure 7. Effect of changing $\mu_{\max }^{\prime}$ in model 2 (with substrate inhibition) on removal efficiency (RE). Toluene-contaminated air volumetric loading is $35.6 \mathrm{~m}^{3} / \mathrm{m}^{3}$ biofilter $/ \mathrm{h}$, inlet toluene gas-phase concentration is $3.01 \mathrm{~g} / \mathrm{m}^{3}, \mu_{\text {max,experimental }}^{\prime}$ is $0.58 \mathrm{~h}^{-1}$.

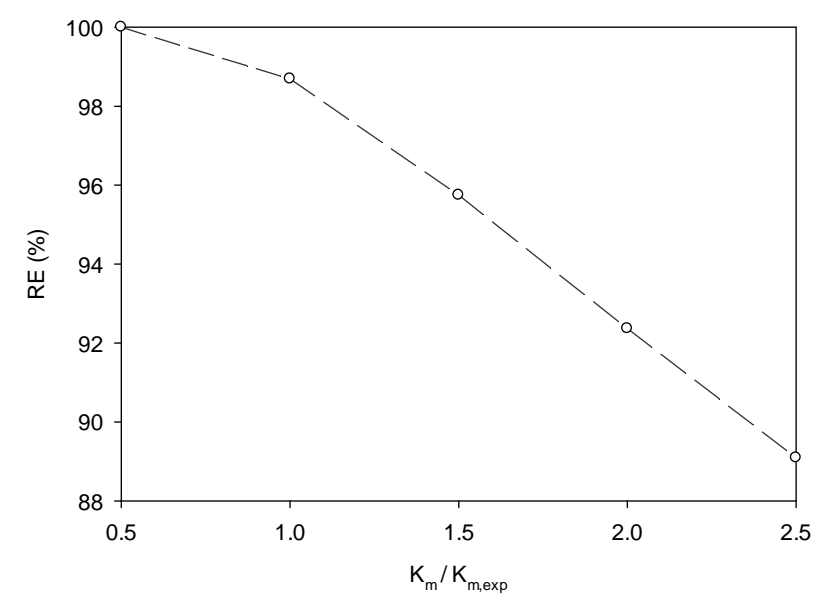

Figure 8. Effect of changing $K_{m}$ in model 1 (no substrate inhibition) on removal efficiency (RE). Toluene-contaminated air volumetric loading is $77.6 \mathrm{~m}^{3} / \mathrm{m}^{3}$ biofilter $/ \mathrm{h}$, inlet toluene gas-phase concentration is $4.6 \mathrm{~g} / \mathrm{m}^{3}, K_{m \text {,experimental }}$ is $1.24 \mathrm{~g} / \mathrm{m}^{3}$. 
same trend was observed at different inlet toluene gasphase concentrations. In case of model 2 with substrate inhibition, the effect of changing $K_{m}$, while keeping other parameters in Table 2 constant, is shown in Figure 9 for inlet toluene gas-phase concentration is $3.01 \mathrm{~g} / \mathrm{m}^{3}$. Again, an increase in the value of the Michaelis-Menten constant $\left(K_{m}\right)$ results in a decrease in removal efficiency. Since model 3 is very similar to model 2 , the effect of changing $K_{m}$ will be the same as in case of model 2 .

\subsubsection{Effect of Decay Rate (a)}

The effect of changing the decay rate on removal efficiency in model 1 is shown in Figure 10. The other pa-

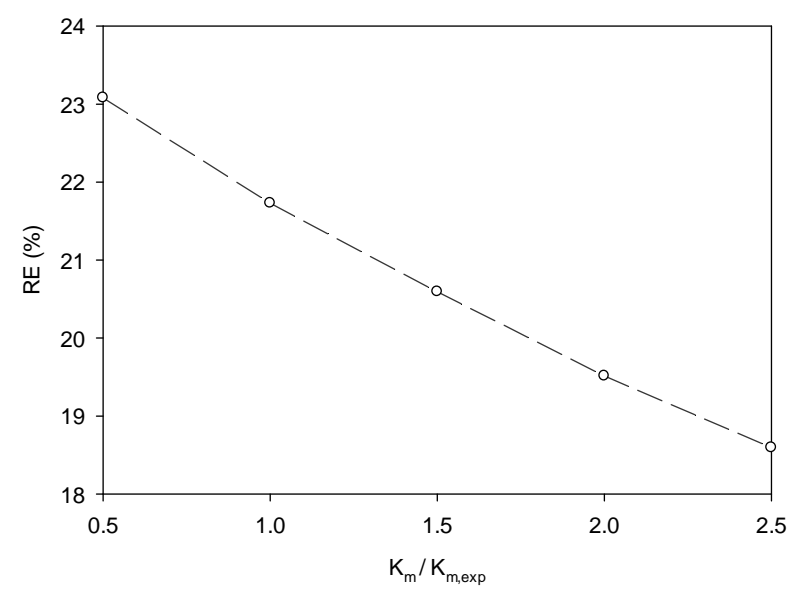

Figure 9. Effect of changing $K_{m}$ in model 2 (with substrate inhibition) on removal efficiency (RE). Toluene-contaminated air volumetric loading is $35.6 \mathrm{~m}^{3} / \mathrm{m}^{3}$ biofilter/h, inlet toluene gas-phase concentration is $3.01 \mathrm{~g} / \mathrm{m}^{3}, K_{m \text {,experimental }}$ is $5.34 \mathrm{~g} / \mathrm{m}^{3}$, experimental data adopted from Park and Jung [12].

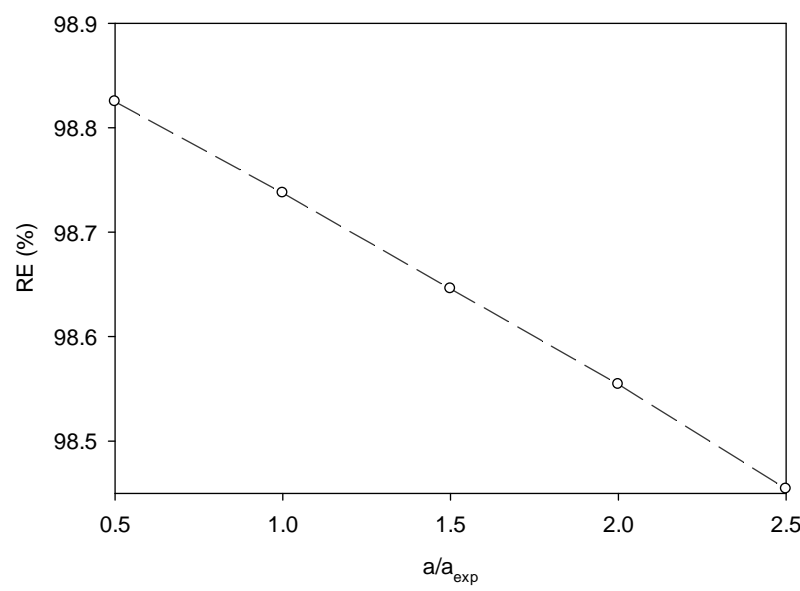

Figure 10. Effect of changing decay rate " $a$ " in model 1 (no substrate inhibition) on removal efficiency (RE). Toluenecontaminated air volumetric loading is $77.6 \mathrm{~m}^{3} / \mathrm{m}^{3}$ biofilter $/ \mathrm{h}$, inlet toluene gas-phase concentration is $4.6 \mathrm{~g} / \mathrm{m}^{3}, a_{\mathrm{ex}-}$ perimental is $0.0017 \mathrm{~h}^{-1}$, experimental data adopted from Aizpuru et al. [29]. rameters were kept constant as in Table 1. As expected, the higher the decay rate of the biomass, the lower the removal efficiency in case of model 1 . Similarly, the effect of changing the decay rate on removal efficiency in model 2 is shown in Figure 11. Model 3 also gave similar results. In all cases, for the range of decay rates selected, the effect on the removal efficiency was not very significant. Nevertheless, the conditions of the biofilter must be properly selected in order to minimize biomass decay.

\subsubsection{Effect of Inhibition Constant $\left(K_{I}\right)$}

Inhibition is an important factor in model 2 for the prediction of gas-phase toluene concentration along the biofilter height. The effect of changing the inhibition constant $\left(K_{I}\right)$ on removal efficiency in model 2 is shown in Figure 12. An increase in the inhibition constant $\left(K_{I}\right)$, leads to an increase in toluene removal efficiency in model 2. The results from with model 3 were similar. Again, since model 3 is very similar to model 2, the effect of changing $K_{m}$ will be the same as in case of model 2.

\section{Conclusion}

In this work, important literature on recent biofilter models are reviewed. The toluene biofilter model of $\mathrm{Li}$ and De Visscher [22] is solved and compared with a new experimental data of Zamir et al. [28]. The model is in very good agreement with the experimental data. Thus, the model can be used as a good approximation for full scale biofilter design calculations, particularly for toluene removal. A sensitivity analysis of the three models is performed. Maximum specific growth rate, kinetic con-

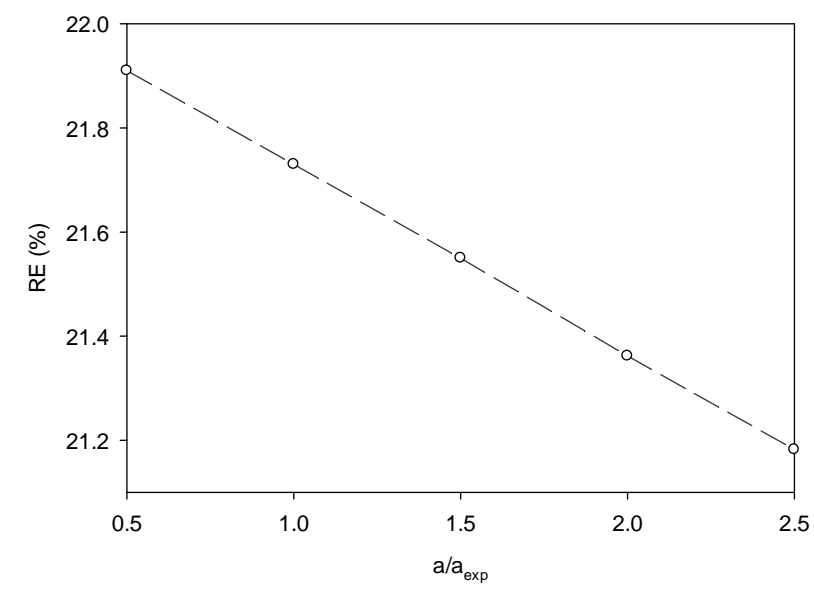

Figure 11. Effect of changing $K_{m}$ in model 2 (with substrate inhibition) on removal efficiency (RE). Toluene-contaminated air volumetric loading is $35.6 \mathrm{~m}^{3} / \mathrm{m}^{3}$ biofilter $/ \mathrm{h}$, inlet toluene gas-phase concentration is $3.01 \mathrm{~g} / \mathrm{m}^{3}, a_{\text {experimental }}$ is $0.0017 \mathrm{~h}^{-1}$, experimental data adopted from Park and Jung [12]. 


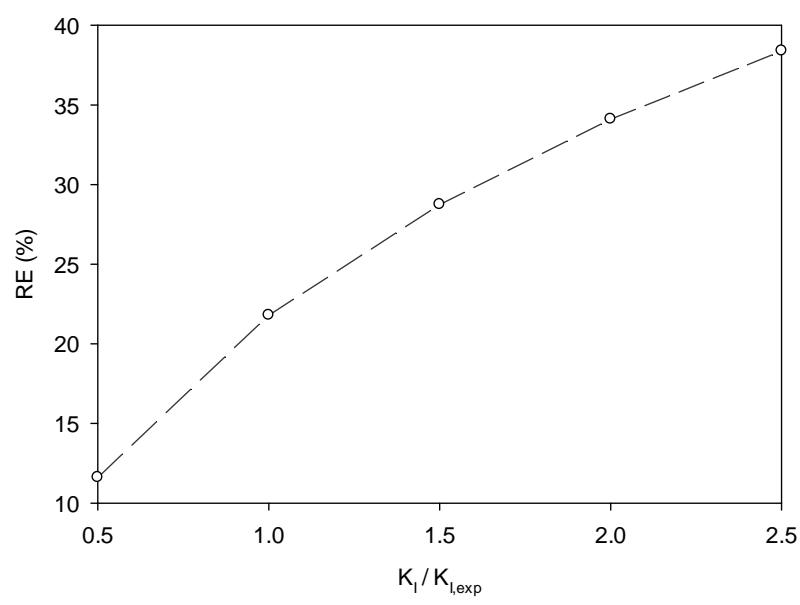

Figure 12. Effect of changing $K_{I}$ in model 2 (with substrate inhibition) on removal efficiency (RE). Toluene-contaminated air volumetric loading is $35.6 \mathrm{~m}^{3} / \mathrm{m}^{3}$ biofilter/h, inlet toluene gas-phase concentration is $3.01 \mathrm{~g} / \mathrm{m}^{3}, K_{I \text {,experimental }}$ is $2.66 \mathrm{~g} / \mathrm{m}^{3}$, experimental data adopted from Park and Jung [12].

stant $\left(K_{m}\right)$, and inhibition constants are more sensitive to removal efficiency than decay rate constant. Thus, accurate estimation of these parameters is important. Although the model does not provide an insight into the nature of the limiting factors such as oxygen effects and diffusion limitations involved in the biofiltration process, the model is simple and will enable designing of biofilters using fewer biofilter parameters.

\section{Acknowledgements}

The authors acknowledge the support of the Chemical Engineering Department at the American University of Sharjah.

\section{REFERENCES}

[1] T. Nukunya, J. S. Debinny and T. T. Tsotsis, "Application of a Pore Network Model to a Biofilter Treating Ethanol Vapor," Chemical Engineering Science, Vol. 60, No. 3, 2005, pp. 665-667. doi:10.1016/j.ces.2004.08.038

[2] B. V. Babu and S. Raghuvanshi, "Simulation Studies on Transient Model for Biofilter Operated in Periodic Mode," Journal on Engineering and Technology, Vol. 1, No. 4, 2006, pp. 72-76.

[3] C. R. Soccol, et al., "Biofiltration: An Emerging Technology," Indian Journal of Biotechnology, Vol. 2, No. 2, 2003, pp. 396-410.

[4] Z. Shareefdeen and A. A. Shaikh, "Analysis and Comparison of Biofilter Models," Chemical Engineering Journal, Vol. 65, No. 1, 1998, pp. 55-61.

[5] J. S. Devinny and J. Ramesh, "A Phenomenological Review of Biofilter Models," Chemical Engineering Journal, Vol. 113, No. 2-3, 2005, pp. 187-196. doi:10.1016/j.cej.2005.03.005
[6] M. Hirai, M. Ohtake and M. Shoda, "Removal Kinetics of Hydrogen Sulfide, Methanethiol and Dimethyl Sulfide by Peat Biofilters," Journal of Fermentation Bioengineering, Vol. 70, No. 5, 1990, pp. 334-339. doi:10.1016/0922-338X(90)90145-M

[7] S. P. P. Ottengraf and A. H. C. van den Oever, "Kinetics of Organic Compound Removal from Waste Gases with a Biological Filter," Biotechnology and Bioengineering, Vol. 25, No. 12, 1983, pp. 3089-3102. doi:10.1002/bit.260251222

[8] Z. Shareefdeen, B. C. Baltzis, Y. S. Oh and R. Bartha, "Biofiltration of Methanol Vapor," Biotechnology and Bioengineering, Vol. 41, No. 5, 1993, pp. 512-524. doi:10.1002/bit.260410503

[9] Z. Shareefdeen and B. C. Baltzis, "Biofiltration of Toluene Vapor under Steady-State and Transient Conditions: Theory and Experimental Results," Chemical Engineering Science, Vol. 49, No. 24, 1994, pp. 4347-4360. doi:10.1016/S0009-2509(05)80026-0

[10] M. A. Deshusses, G. Hamer and I. J. Dunn, "Behavior of Biofilters for Waste Air Biotreatment. 1. Dynamic Model Development," Environmental Science Technology, Vol. 29, No. 4, 1995, pp. 1048-1058. doi: $10.1021 / \mathrm{es} 00004 \mathrm{a} 027$

[11] M. A. Deshusses, G. Hamer and I. J. Dunn, "Behavior of Biofilters for Waste Air Biotreatment. 2. Experimental Evaluation of a Dynamic Model," Environmental Science Technology, Vol. 29, No. 4, 1995, pp. 1059-1068. doi: $10.1021 / \mathrm{es} 00004 \mathrm{a} 028$

[12] O. Park and I. Jung, "A Model Study Based on Experiments on Toluene Removal under High Load Condition in Biofilters," Biochemical Engineering Journal, Vol. 28, No. 3, 2006, pp. 269-274. doi:10.1016/j.bej.2005.11.011

[13] C. P. Yang, H. Chen, W. Qu, Y. Y. Zhong, X. Zhu and M. T. Suidan, "Modeling Biodegradation of Toluene in Rotating Drum Biofilter", Water Science Technology, Vol. 54, No. 9, 2006, pp. 137-144. doi:10.2166/wst.2006.860

[14] Q. Liao, X. Tian, R. Chen and X. Zhu, "Mathematical Model for Gas-Liquid Two-Phase Flow and Biodegradation of a Low Concentration Volatile Organic Compound (VOC) in a Trickling Biofilter," International Journal of Heat and Mass Transfer, Vol. 51, No. 7-8, 2007, pp. 17801792. doi:10.1016/j.ijheatmasstransfer.2007.07.007

[15] J. Chen, Y. Jiang, H. Sha and W. Zhang, "Dynamics Model for Nitric Oxide Removal by a Rotary Drum Biofilter," Journal of Hazardous Materials, Vol. 168, No. 2-3, 2009, pp. 1047-1052. doi:10.1016/j.jhazmat.2009.02.159

[16] G. Spigno, M. Zilli and C. Nicolella, "Mathematical Modeling and Simulation of Methanol Degradation in Biofilters," Biochemical Engineering Journal, Vol. 19, No. 3, 2004, pp. 267-275. doi:10.1016/j.bej.2004.02.007

[17] G. Baquerizo, et al., "A Detailed Model of a Biofilter for Ammonia Removal: Model Parameters Analysis and Model Validation," Chemical Engineering Journal, Vol. 113, No. 2-3, 2005, pp. 205-214. doi:10.1016/j.cej.2005.03.003

[18] C. Lu, K. Chang and S. Hsu, "A Model for Treating Isopropyl Alcohol and Acetone Mixtures in a Trickle-Bed 
Air Biofilter," Process Biochemistry, Vol. 39, No. 12, 2004, pp. 1849-1858. doi:10.1016/j.procbio.2003.09.019

[19] K. Chmiel, et al., "Periodic Operation of Biofilters. A Concise Model and Experimental Validation," Chemical Engineering Science, Vol. 60, No. 11, 2005, pp. 28452850. doi:10.1016/i.ces.2004.12.035

[20] EPA, "Chemical Summary of Toluene," 2011. www.epa.gov/chemfact/s_toluen.txt

[21] K. Singh, R. S. Singh and S. N. Upadhyay, "Biofiltration of Toluene Using Wood Charcoal as the Biofilter Media," Bioresource Technology, Vol. 101, No. 11, 2009, pp. 39473951. doi:10.1016/j.biortech.2010.01.025

[22] G. Q. Li and A. De Visscher, "Toluene Removal Biofilter Modeling," Air and Waste Management Association, Vol. 58, No. 7, 2008, pp. 947-956. doi:10.3155/1047-3289.58.7.947

[23] A. De Visscher and O. Van Cleemput, "Simulation Model for Gas Diffusion and Methane Oxidation in Landfill Cover Soils," Waste Management, Vol. 23, No. 7, 2003, pp. 581-591. doi:10.1016/S0956-053X(03)00096-5

[24] S. J. Pirt, "Principles of Microbe and Cell Cultivation," Blackwell Scientific, Oxford, 1975.

[25] J. S. Devinny, M. A. Deshusses and T. S. Webster, "Biofiltration for Air Pollution Control," CRC Press, Boca Raton, 1999.

[26] J. B. S. Haldane, "Enzymes," Longmans, Green, New York, 1930.

[27] M. O. Pereira, M. Kuehn, S. Wuertz, T. Neu and L. F. Melo, "Effect of Flow Regime on the Architecture of a Pseudomonas Fluorescens Biofilm," Biotechnology and Bioengineering, Vol. 78, No. 2, 2002, pp. 164-171. doi:10.1002/bit.10189

[28] S. M. Zamir, R. Halladj and B. Nasernejad, "Removal of Toluene Vapors using a Fungal Biofilter under Intermittent Loading," Process Safety and Environmental Protection, Vol. 89, No. 1, 2011, pp. 8-14. doi:10.1016/j.psep.2010.10.001

[29] A. Aizpuru, B. Dunat, P. Christen, R. Auria, I. Garc1a-Pena and S. Revah, "Fungal Biofiltration of Toluene on Ceramic Rings," Journal of Environmental Engineering, Vol. 131, No. 3, 2005, pp. 396-402. doi:10.1061/(ASCE)0733-9372(2005)131:3(396)

[30] L. F. Bautista, A. Aleksenko, M. Hentzer, A. SanterreHenriksen and J. Nielsen, "Antisense Silencing of the CreA Gene in Aspergillus Nidulans," Applied and Environmental Microbiology, Vol. 66, No. 10, 2000, pp. 4579-4581. doi:10.1128/AEM.66.10.4579-4581.2000
[31] M. Carlsen, A. B. Spohr, J. Nielsen and J. Villadsen, "Morphology and Physiology of an $\alpha$-Amylase Producing Strain of Aspergillus Oryzae during Batch Cultivations," Biotechnology and Bioengineering, Vol. 49, No. 3, 1996, pp. 266-276. doi:10.1002/(SICI)1097-0290(19960205)49:3<266::AIDBIT4>3.0.CO;2-I

[32] T. D. Reynolds and P. A. Richards, "Unit Operations and Processes in Environmental Engineering," 2nd Edition, PWS Press, Boston, 1996.

[33] "EPA Online Tools for Site Assessment CalculationsEstimated Henry's Law Constant-OSWER Method," U.S. Environmental Protection Agency, 2011.

http://www.epa.gov/ATHENS/learn2model/part-two/onsi te/esthenry.html

[34] K. F. Reardon, D. C. Mosteller and J. D. Bull Rogers, "Biodegradation Kinetics of Benzene; Toluene, and Phenol as Single and Mixed Substrates for Pseudomonas Putida F1," Biotechnology \& Bioengineering, Vol. 69, No. 4, 2000, pp. 385-400.

doi:10.1002/1097-0290(20000820)69:4<385::AID-BIT5> 3.0.CO;2-Q

[35] R. Mirpuri, W. Jones and J. D. Bryers, "Toluene Degradation Kinetics for Planktonic and Biofilm: Growth Cells of Pseudomonas putida 54G," Biotechnology and Bioengineering, Vol. 53, No. 6, 1997, pp. 535-546. doi:10.1002/(SICI)1097-0290(19970320)53:6<535::AIDBIT1>3.0.CO;2-N

[36] Y. B. Choi, J. Y. Lee and H. S. Kim, "A Novel Bioreactor for the Biodegradation of Inhibitory Aromatic Solvents: Experimental Results and Mathematical Analysis," Biotechnology and Bioengineering, Vol. 40, No. 11, 1992, pp. 1403-1411. doi:10.1002/bit.260401115

[37] F. X. Prenafeta-Bold, A. Kuhn, D. M. A. M. Luykx, H. Anke, J. W. Van Groenestijn and J. A. M. De Bont, "Isolation and Characterization of Fungi Growing on Volatile Aromatic Hydrocarbons as Their Sole Carbon and Energy Source," Mycological Research, Vol. 105, No. 4, 2001, pp. 477-484. doi:10.1017/S0953756201003719

[38] A. Vergara-Fernandez, L. L. Molina, N. A. Pulido and G. Aroca, "Effects of Gas Flow Rate, Inlet Concentration and Temperature on the Biofiltration on Toluene Vapors," Journal of Environmental Management, Vol. 84, No. 2, 2007, pp. 115-122. doi:10.1016/j.jenvman.2006.04.009

[39] S. M. Maliyekkal, E. R. Rene, L. Philip and T. Swaminathan, "Performance of BTX Degraders under Substrate Versatility Conditions," Journal of Hazardous Materials, Vol. 109, No. 1-3, 2004, pp. 201-211. doi:10.1016/j.jhazmat.2004.04.001 